\title{
Summary of Results
}

Introduction. The research project proposed to synthesize new metal complexes with sulfido, disulfido and other types of reactive sulfur ligands, and to explore the joint reactivity of metal and sulfur ligands with hydrogen and organic molecules. The overall objective was to investigate reaction pathways relevant to those observed for the heterogeneous metal sulfide catalysts which promote hydrogen activation, hydrogenation-dehydrogenation of organic substrates, and hydrogenolysis of carbonheteroatom bonds. ${ }^{1}$ Particular emphasis was placed on CpRe derivatives (where Cp might be $\mathrm{C}_{5} \mathrm{H}_{5}$ or alkylated versions) so that comparisons could be made with the previously studied CpMo complexes, which showed extensive reactivity at the sulfur ligands. ${ }^{2}$ Heterogeneous rhenium sulfides generally show higher catalytic activity than molybdenum sulfides, and this is attributed, in part, to the weaker Re-S bond strength, relative to the moybdenum-sulfur bond. ${ }^{3}$ In our studies of discrete Re-sulfide complexes, we have also observed evidence for weaker Re-S bonds relative to the molybdenum systems. In addition we have characterized novel hydrogen activation by rhenium sulfido complexes, as well as carbon-hydrogen, carbon-sulfur and metal sulfur bond cleavage reactions.

During this project period work supported by a previous DOE grant was also completed in which the activation of pyrrole heterocycles by metal complexes was studied. As detailed in the final report for that project, several types of metal-pyrrole complexes were synthesized, and regioselective activations toward both nucleophilic and electrophilic reagents were identified.

Hydrogen Activation. The complex $\mathrm{Cp}^{\prime} \mathrm{ReCl}_{2} \mathrm{~S}_{3}$ was synthesized in ca $70 \%$ yield and characterized by an X-ray diffraction study which confirms that the complex contains a $\eta^{2}$-trisulfide ligand. The cyclic voltammogram of $C \mathrm{p}^{\prime} \mathrm{ReCl}_{2} \mathrm{~S}_{3}$ shows a wide window of redox stability with an irreversible reduction wave at $-0.97 \mathrm{~V}$ and an irreversible oxidation at $+1.03 \mathrm{~V}$ vs Fc. Nevertheless, the complex undergoes a facile reaction with hydrogen at $50^{\circ} \mathrm{C}$ as shown in Eq. 1 .

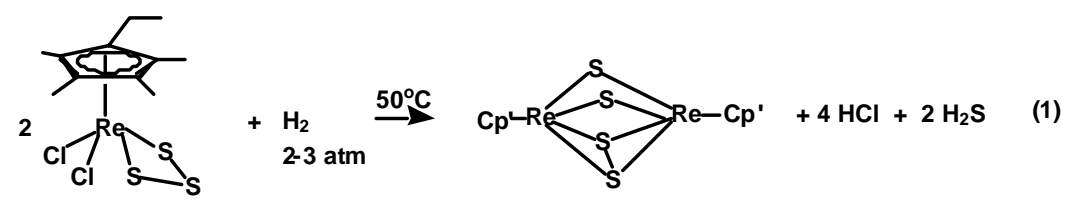

This reaction is of interest because it is the first example of the hydrogenolysis of a discrete metal polysulfide complex to produce $\mathrm{H}_{2} \mathrm{~S}$, a reaction also observed for heterogeneous rhenium sulfides. The reaction contrasts with those of related Cpmolybdenum complexes with sulfide ligands, which also activate hydrogen, but generally form hydrosulfido products without $\mathrm{H}_{2} \mathrm{~S}$ elimination.

C-H and C-S Cleavage Reactions. New mononuclear Cp'Re(dithiolate) complexes such as $\mathrm{Cp}^{\prime} \mathrm{ReCl}_{2}\left(\mathrm{SC}_{2} \mathrm{H}_{4} \mathrm{~S}\right)$, $\mathbf{1}$, have been prepared and characterized and have been found to display a very interesting range of reactions. The thermal reaction of $\mathbf{1}$ involves the dehydrogenation of the alkanedithiolate ligand to form $\mathrm{Cp}^{\prime} \mathrm{ReCl}_{2}(\mathrm{SCH}=\mathrm{CHS}), 2$ as well as a competing elimination of olefin from the dithiolate ligand in $\mathbf{1}$ as summarized in Eq. 2. 

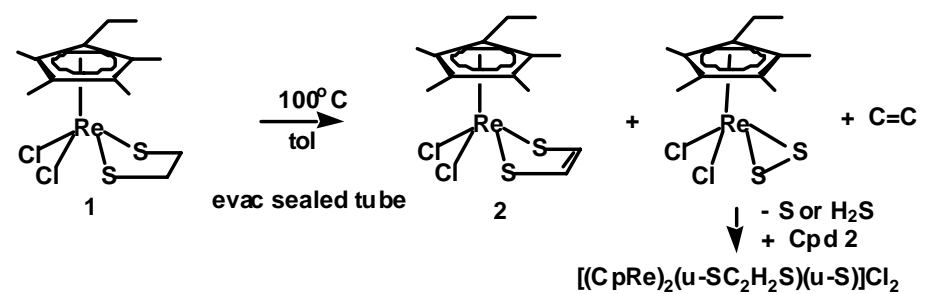

(2)

Kinetic data for the thermal reactions of $\mathbf{1}$ and related derivatives in $\mathrm{d}^{8}$-toluene were obtained by NMR spectroscopy and the thermal reaction of $\mathbf{1}$, followed through 3 half lives, was found to be first order in $\mathbf{1}$. Rate constants were determined over a temperature range of 80 to $108^{\circ} \mathrm{C}$. An Eyring plot provided the following activation parameters: $\Delta \mathrm{H}^{\ddagger}$ $=121 \pm 5 \mathrm{~kJ} / \mathrm{mol}$ and $\Delta \mathrm{S}^{\ddagger}=-24 \pm 12 \mathrm{~J} / \mathrm{mole} \mathrm{K}$.

On the basic of kinetic and related studies, the mechanism is proposed to involve a sequential series of reactions as shown in Scheme 1.

$$
\underset{\mathbf{1}}{\mathrm{Cp} \mathrm{ReCl}_{2}\left(\mathrm{SC}_{2} \mathrm{H}_{4} \mathrm{~S}\right)} \rightarrow \quad \mathrm{H}_{2} \mathrm{C}=\mathrm{CH}_{2}+{ }^{\mathrm{C}} \mathrm{Cp}^{\prime} \mathrm{ReCl}_{2} \mathrm{~S}_{2} "
$$

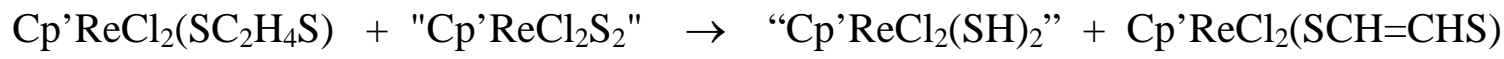

Scheme 1

In this scheme, the olefin extrusion reaction is proposed to produce a reactive Redisulfide or Re-bis(sulfido) intermediate which serves as an oxidant for the dithiolate complex 1. The ability of the bis sulfido complex to dehydrogenate hydrocarbons is a unique feature and several additional dehydrogenation reactions with this system have been characterized, including the oxidation of other dithiolate complexes, of tetrahydronaphthalene and of cyclohexadiene. Precedents for the role of metal sulfides in dehydrogenation reactions have been reported for heterogeneous metal sulfide surfaces. ${ }^{13}$ This work has begun to provide information about the electronic and structural features necessary for such reactivity.

Carbon Sulfur Bond Formation. When the thermal reaction of 1 was carried out in the presence of excess dry ethene a new reaction was observed as shown in Eq. $3 .^{5}$ The dithiolate ligand is displaced by incoming olefin to form the organic product,

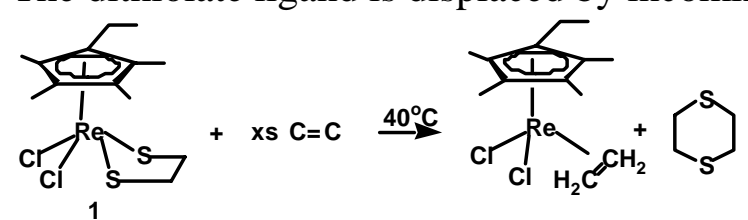

1,4-dithiane. The Re product is identified as Cp'Re(alkene) $\mathrm{Cl}_{2}$ on the basis of NMR and mass spectroscopic data. Similar reactions with alkynes have been found to form unsaturated 6-membered rings and reactions with 1,3 dithiolate complexes form the organic 7-membered rings. To our knowledge the formation of cyclic bis-thioethers by the reactions of an alkene or alkyne with a discrete dithiolate metal complex has not been reported previously.

Reactions of the rhenium dithiolate complexes with other metal fragments have been studied as a pathway to heteronuclear clusters. For example, the first example of a 
$\mathrm{Pt}_{2} \mathrm{ReS}_{2}$ complex and examples of $\mathrm{Re} / \mathrm{Ag} / \mathrm{S}$ coordination polymers have been synthesized and characterized.

Conclusions. A series of new rhenium complexes with sulfido, disulfido, and thiolate ligands have been synthesized and characterized. The complexes have shown novel patterns of reactivity at the sulfur ligands that include hydrogen activation and addition, dehydrogenations, and carbon -sulfur bond formation. Systematic studies of sulfur ligand reactivity as the coligands in these rhenium complexes were varied have established electronic features that favor the novel ligand based reactivity. This series of complexes provides a model system for aspects of rhenium-sulfide surface reactivity, and have led to the suggestion of new mechanistic possibilities.

\section{Publications Supported by DOE Grant DOE FG03-95ER14567:}

K. Parker, V. Carperos, M. Rakowski DuBois, "Syntheses of $\eta^{5}$-Tetramethylpyrrole Derivatives of Ta (V) Containing $\eta^{1}$-Pyrrolyl and Indolyl Ligands." Inorg. Chemistry 1996, 35, 3228-3234.

M. Rakowski DuBois, "Reactions of Cationic Dinuclear Molybdenum Complexes Containing $\mu$-Sulfido and $\mu$-Thiolate Ligands." J. Cluster Science, 1996, 7, 293315.

M. Rakowski DuBois, B. Jagirdar, B. Noll, S. Dietz, "Syntheses, Structures and Reactions of Cyclopentadienyl Metal Complexes with Bridging Sulfur Ligands," ACS Symposium Series, "Transition Metal Sulfur Chemistry," E. I. Stiefel, K. Matsumoto, Eds., American Chemical Society: Washington D.C., 1996, Vol. 653, 269-281.

S. Chen. B. C. Noll, M. Rakowski DuBois, "Iridium (I) Complexes Containing the $\eta^{1}$-(N)-Bonded Indolyl Ligand," Organometallics, 1997 16, 1089-1092.

B. B. Kaul, N. Noll, S. Renshaw, M. Rakowski DuBois, "Dinuclear $\mu$-Sulfido Complexes of Molybdenum with Dimethylaminoethyl-Substituted Cyclopentadienyl Ligands, Organometallics, 1997, 16, 1604-1611.

S. Chen, L Vasquez, B. C. Noll, and M. Rakowski DuBois, "Syntheses and Characterizations of Mononuclear Indoline Complexes. Studies of $\sigma$ and $\pi$ Bonding Modes," Organometallics, 1997, 16, 1757-1764.

M. Rakowski DuBois, K. Parker, C. Ohman, and B. C. Noll, "Nucleophilic Substitution of $\eta^{5}$-Pyrrolyl Ligands in Ru(II) Complexes," Organometallics, 1997, $16,2325-2334$. 
M. Rakowski DuBois, "Carbon-Chalcogen Bond Cleavage Reactions Characterized for Dinuclear Sulfur-Bridged Cyclopentadienyl Molybdenum Complexes,"

Polyhedron, 1997, 16, 3089-3098.

M. Rakowski DuBois, "Catalysis by Sulfido Bridged Dimolybdenum Complexes," in "Catalysis by Di- and Polynuclear Metal Cluster Complexes" R. D. Adams, F. A. Cotton, Eds., VCH Publishers, New York, 1998, 127-143.

M. Rakowski DuBois, "The Activation of $\eta^{5}$-Pyrrole Complexes Toward Nucleophilic Attack," Coordination Chemistry Reviews, 1998, 174, 191-205.

L.. D. Vasquez, B. C. Noll, M. Rakowski DuBois, "Mononuclear Indoline Complexes 2. Synthesis, Structure and Reactivity of [(Cymene)Ru( $\eta^{1}-\mathrm{N}-$ indoline $\left.\left(\mathrm{CH}_{3} \mathrm{CN}\right)_{2}\right](\mathrm{OTf})_{2}$," Organometallics, 1998, 17, 976-981.

M. Rakowski DuBois, L. D. Vasquez, L. Peshleherbe, B. C. Noll, "Regioselective Electrophilic Substitution and Addition Reactions at an N-Coordinated Pyrrolyl Ligand in $\left(\mathrm{PMe}_{2} \mathrm{Ph}\right)_{3} \mathrm{Cl}_{2} \mathrm{Re}\left(\mathrm{NC}_{4} \mathrm{H}_{4}\right)$," Organometallics, 1999, 18, 2230-2240.

M. Rakowski DuBois, L. D. Vasquez, R. F. Ciancanelli, and B. C. Noll, "Electrophilic Substitution of Nitrogen Heterocycles by Molybdenum Sulfide Complexes," Organometallics, 2000, 19, 3507-3515.

J. Kanney, B. C. Noll, M. Rakowski DuBois, "Reactions of Thiiranes and a Thietane with a High Valent Metal Chloride," Organometallics, 2000, 19, 49254928.

Y. Nishibayashi, I. Wakiji, K. Hirata, M. Rakowski DuBois, and M. Hidai, "Protonation of Coordinated $\mathrm{N}_{2}$ on Tungsten with $\mathrm{H}_{2}$ Mediated by Sulfido-Bridged Dinuclear Molybdenum Complexes," Inorganic Chemistry, 2001, 40, 578-580.

L. D. Vasquez, B. C. Noll, and M. Rakowski DuBois, "Synthesis and Characterization of a Tetranuclear Cyclopentadienyl Molybdenum Compound with a $\mu$-4-Sulfido Ligand," Inorganic Chemistry, 2001, 40, 1391-1393.

Sarah E. Hobert, B. C. Noll, M. Rakowski DuBois, "Synthesis of a Re(V) Polysulfide Complex and a Study of its Reactivity with Hydrogen," Organometallics 2001, 20, 1370-1375. 
S. Hobert Pawlicki, B. C. Noll, M. Rakowski DuBois, "Synthesis of a RePt 2 Complex with Bridging Sulfido Ligands," J. Coord. Chem., 2003, 56, 41-47.

J. A. Kanney, B. C. Noll, M. Rakowski DuBois, "Reactions of Dithiolate Ligands in Mononuclear Complexes of Re(V)," J. Am. Chem. Soc. 2002, 124. 9878-9886.

J. A. Kanney, B. R. Jagirdar, B. C. Noll, and M Rakowski DuBois, "Reactions of DIthiolate Ligands in Mononuclear Complexes of Rhenium(V). 2.

Cp'ReCl2(SC3H6S) and Related Derivatives,” Organometallics 2003, 22, 111-117.

S. H. Pawlicki, B. C. Noll, J. A. Kanney, and M. Rakowski DuBois, Syntheses of a Cp'Re=S Derivative and More Complex Products," Inorganic Chemistry, 2003, 42, 1556-1563.

S. Hobert Pawlicki, M. Rakowski DuBois, "Sites of Electrophilic Attack on $\mathrm{Cp}^{\prime} \mathrm{Re}=\mathrm{X}\left(\mathrm{SC}_{2} \mathrm{H}_{4} \mathrm{~S}\right)$ Complexes, $\mathrm{X}=\mathrm{S}$ and NMe," Manuscript in preparation.

T. Laverty, G. Jacobsen, M. Rakowski DuBois, "Facile Oxidation of 1,2Diamidoethane Ligands in Cp'Re Complexes," Manuscript in preparation.

\section{PhD Theses}

Sylvia Chen, "Synthesis and Reactivity of Transition Metal Complexes of Indole and Related Nitrogen Heterocycles," University of Colorado, 1996.

Lisa Vasquez, "Synthesis and Reactivity of Transition Metal Complexes Containing Nitrogen Heterocycles," University of Colorado, 1998.

Claire Ohman, "Synthesis and Characterization of Metal Complexes with Sulfur and Nitrogen-Containing Ligands," University of Colorado, 2001.

Sarah Hobert Pawlicki, "Synthesis and Reactivity of Rhenium Sulfido and Polysulfido Complexes," University of Colorado, 2002.

Jeffery Kanney, "Synthesis and Reactivity Studies of Rhenium Complexes with Sulfur Containing Organic Ligands," Univeristy of Colorado, 2002.

\section{Papers Presented at Conferences}

M. Rakowski DuBois, S. Pawlicki, J. Kanney, B. Noll, "Metal and Ligand Based Reactivity in Rhenium Complexes with Thiolate and Sulfido Ligands," 225th ACS National Meeting, New Orleans, LA, Mar, 2003. 
M. Rakowski DuBois, J. A. Kanney, "Preparation and Reactions of a New Series of $\operatorname{Re}(V)$ Derivatives Containing Dithiolate Ligands, , 223 ACS National Meeting, Orlando, FL Apr, 2002.

S. E. Hobert, M. Rakowski DuBois, B. C. Noll, "Synthesis of the Re(V) Sulfido Complex $\mathrm{CpReCl}_{2} \mathrm{~S}_{3}$ and Reactivity with Dihydrogen to form Dinuclear Rhenium Complexes," 220th ACS National Meeting, Washington DC, Aug. 2000.

M. Rakowski DuBois, L. Vasquez, L. Peslherbe, "The Activation of Pyrrole by Metal Complex Coordination," ACS National Meeting, Boston, MA, Aug. 1998.

L. Vasquez, B. C. Noll, and M. Rakowski DuBois, "Acid Base Properties and Reactivities of Ru(II) Complexes with N-Bonded Saturated Heterocycles, " ACS National Meeting, Las Vegas, NV Aug., 1997.

K. G> Parker, C. Ohman, S. Chen, B. Noll, B. Jagirdar, M. Rakowski DuBois, "Reactions of Transition Metal Complexes with Nitrogen Heterocycles," ACS National Meeting, New Orleans, LA, Mar., 1996. 